\title{
0102 RISK FACTORS AND SEATBELT USE IN ARGENTINA
}

M Vacchino* Correspondence: National Institute of Epidemiology, Dr Juan H. Jara, Ituzaingo 3520, Mar del Plata (Buenos Aires), 7600, Argentina

10.1136/ip.2010.029215.102

Few studies examined the use of seatbelt and risk factors in lower- or middle-income countries. We investigated the associations between no seatbelt use and age, gender, education, obesity, excessive ingestion of alcohol in the past 30 days and region in Argentina.

In 2005 National Survey of Risk Factors, seatbelt use was asked "How often do you use seatbelts when you drive or ride in a car? Responses were coded dichotomously (always $=0$ vs less than always $=1$ ).

Multivariable logistic regression was used to calculate ODs and $95 \%$ CIs for not using seatbelt and sex, age and education level. Because interaction effects were evident for sex, obesity, alcohol intake and region, we performed a stratified analysis by sex using as covariables age, education level, obesity, alcohol intake and region. Adjusted ODs for no seatbelt use were 1.23 (1.11 to 1.36) for women, 3.44 (2.83 to 4.17) for education level less than primary school) and 2.61 (2.20 to 3.10) for 18-24 age group, among others. Stratified analysis by sex showed strong associations between increased BMI and no seatbelt use in extremely obese women, $\mathrm{OR}=2.50$ (1.30 to 4.81), and Northwest, $\mathrm{OR}=6.10$ (5.08 to 7.33). In men, significant associations with alcohol abuse $\mathrm{OR}=1.58$ (1.28 to 1.97). Effective preventive interventions are needed to promote seatbelt use among women, young and less educated people and to control the alcohol intake, especially in certain country's regions. 